\title{
Utility of Metric Conversion for Success in Introductory College Science Courses
}

\author{
Sonali Raje ,** $^{\text {, }}$ \\ ${ }^{1}$ Department of Chemistry, Towson University, Towson, MD, USA \\ *Correspondence: Department of Chemistry, Towson University, Towson, MD, USA. E-mail: sraje@towson.edu
}

Received: March 18, 2019

Accepted: May 3, 2019 Online Published: May 23, 2019

doi:10.5430/jct.v8n2p32

URL: https://doi.org/10.5430/jct.v8n2p32

\begin{abstract}
Cross-connections between the sciences and mathematics are emphasized through the Next Generation Science Standards and the Common Core State Standards in the United States. One topic that is a common bridge between math and science is the concept of measurement and unit conversions in the metric/English system. This article uses a mixed-methods research design attempt to highlight the significance of this topic to demonstrate scientific literacy and for preparing students to be college ready. An analysis of content from college level introductory physical science textbooks, middle and high school math and science teacher surveys, clinical interviews and college studentsurveys are used to show how this critical concept may not be getting the attention it deserves in the US school systems. Furthermore, the critical need to have specific questions related to this topic on standardized state assessments has been suggested. The results indicate the need to reify this topic more extensively over the school years, especially since the metric system of measurement is not a part of daily life in the United States.
\end{abstract}

Keywords: unit conversions, college readiness, cross-cutting concepts, measurement

\section{Introduction}

Over the past decade, there has been a huge impetus to prepare high school students for college and career readiness. Next Generation Science Standards (NGSS) and Common Core State Standards in mathematics education provide guidelines for school systems and emphasize Career and College Readiness for high school graduates to be prepared for college. The CCSS and the NGSS explicitly indicate that students should be able to make interdisciplinary connections between science, mathematics, and engineering content. One of the most fundamental concepts in the physical science disciplines of chemistry and physics with interdisciplinary connections to mathematics; is the ability to understand units of measurement. While the routine system of measurement in the United States is the English system- the language of measurement in science and almost all of the rest of the world is the metric system. Despite the fact that the concept of measurement is listed as part of the NGSS, the standards do not explicitly list the metric system or unit conversions anywhere either as a disciplinary core idea or as a cross-cutting concept of the NGSS. This article is an exploratory case study that attempts to identify the role of unit conversions for successful preparation for introductory science courses and also to understand how unit conversions are currently taught in schools by obtaining a perspective of school science and math teachers. Additionally, the article also explores college students' readiness for unit conversions in introductory college science.

\section{Literature Review}

Conley (2007) has provided an operational definition of college readiness as the level of preparation a student needs to be successful in an introductory college course without remedial intervention. He further suggests that success in an introductory college course can be understood "as completing entry level courses at a level of understanding and proficiency that makes it possible for the student to consider taking the next course in the sequence or the next level of courses in the subject area" (Conley, 2007. p.5). Physical science disciplines require students to routinely perform computational problem-solving. To ensure that incoming students have the required mathematics skills for success in introductory science courses, several institutions often administer their own placement tests or diagnostic 
assessments (Haffner, 1969; Russell, 1994; Angel \& Lalonde, 1998; McFate \& Olmsted, 1999; Legg, Legg, \& Greenbowe, 2001; Wagner, Sasser \& DiBiase, 2002). When students taking these placement tests do not "make the cut" many of them are required to take remedial math courses or equivalent preparatory science coursework prior to taking the courses required for their specific college major. Shumba and Glass (1994) have shown that college faculty teaching introductory courses believe that high school graduates are not well-prepared to take college science courses. Similar results have been reported in physics education by Sadler and Tai (2001). Deampfle (2003) has shown that high attrition rates for students in science, math and engineering majors are linked to variable academic preparation and expectations from college and school faculty. Despite the general understanding and acceptance that a strong math- background is required for success in college science, prior research indicates that there is considerable variability with respect to mathematics content exposure that is provided to students in school (Swanson \& Stevenson, 2002). deAraujo et al. (2013) have shown that even when school teachers use one standardized integrated mathematics curriculum, they have varying ideas about what parts of the curriculum they are supposed to connect and what topics may need to be emphasized in mathematics classes. Over the nation, teachers reported being unable to cover almost $20 \%$ of the content every year (Adodini et al., 2009). Ottmar, Konold, Berry, Grissmer and Cameron (2013) citing Adodini et al. (2009) suggest that if teachers consistently omit $20 \%$ of the content, it is important to determine what concepts may be neglected. Research shows that high school preparation and content coursework in science and mathematics plays a significant role in successfully completing introductory college science courses (West, 1932; Yager, Snider, \& Krajcik, 1988; Reynolds \& Walberg, 1992; Sadler \& Tai, 2001; Weiss, Pasley, Smith, Banilower, \& Heck, 2003, (Gifford \& Harpole, 1986; Hart \& Cottle, 1993; Tai, Sadler, \& Loehr, 2005; Johnson \& Kuennen, 2006; Tai \& Sadler 2007; Schwartz, Sadler, Sonnert, \& Tai, 2009). Although it is commonly accepted that a strong mathematics background is required for success, there is no clear data available as to what specific topics in mathematics are needed for success in introductory physics and chemistry classes. Butterfield, Sutherland and Molyneux-Hodgson (2011) suggest the importance of unit conversions in learning science for vocational students and describe the use of computer-based activities to enhance student learning of this critical concept. In a review paper on metric unit conversions, Dincer and Osmanoglu (2018) have examined 73 prospective science teachers' comfort levels on metric unit conversions by administering a 14 question test which included multiple choice and open response questions. Their findings suggest that these prospective science teachers were not comfortable doing unit conversions beyond anything that required them to convert within base units like grams, meters or liters. Sokolowski (2015) suggests that students taking AP chemistry and physics exams often make mistakes on unit conversions. This is also seen in college introductory physics courses and that when students are explicitly instructed on identifying metric prefixes, their performance on exams improves significantly. In an interesting commentary, Ludwig (2016) has shown how the metric system is a unit system based on the powers of 10 and it is just a subset of the SI system, which is more exhaustive and coherent.

\section{Rationale for the Study}

Several college textbooks use the base unit (meter/gram or liter) as "one" and provide values for the other prefixes based on that. For example, if the base is assigned the unit of 1 , then a microgram is assigned a value of $10^{-6}$, which is meant to show that a microgram is equivalent to a millionth of a gram. However, several instructors have provided anecdotal evidence that students are not able to read it as $10^{6}$ micrograms in a gram, instead many of the students assign fixed values to the prefixes. It is vital to emphasize the magnitudes of the quantities and their relationships between the prefixes and how they can change between quantities. The following question was tested as part of a final exam in chemistry for a cohort of health-science majors at our institution. How many centimeters correspond to $15.68 \mathrm{~km}$ ? Fifty-four students out of $133(41 \%)$ got it wrong. While it is understandable that some students may make careless errors on a test and this may not necessarily reflect their understanding, $41 \%$ wrong respondents is a very high number for something so basic- especially from college students. Conversations with colleagues from other universities in the country during national and regional professional conference meetings anecdotally suggested that this problem was not isolated and it was common among all tiers of public universities and community colleges The research based evidence of the requirement of a strong mathematics background, final exam results on the question of unit conversions from a cohort of student taking an introductory chemistry course and anecdotal evidence from conversations with colleagues within and outside our University indicate that students repeatedly show a discomfort towards unit conversions. The following research questions are posed to address readiness on this topic for science readiness, specifically given the lack of current literature for the role of unit conversions on science readiness. 
1. How is the topic of unit conversions (both within SI and English-SI) being covered in college introductory physical science textbooks and in schools?

2. What are the students' perspectives on the challenges of learning the topic of unit conversions?

\section{Research Methodology}

This exploratory work was conducted in three parts, using multiple methods. Ten different textbooks for introductory physical science courses from different publishers were analyzed. Middle and high school science and mathematics teachers from three different counties in the state of Maryland and the states of Connecticut, Virginia, New York and California were randomly selected for participation. These five states have consistently been ranked at the top in terms of its high school graduation rate as shown by the data obtained from the US Department of Education (USDOE). One hundred and thirty four emails were sent out to STEM teachers from at least three different school districts or counties, from each state. High schools selected had less than $20 \%$ of the total student population subscribed to free and reduced meal programs to minimize data from being skewed due to other potentially impacting factors like socio-economic status for instruction and performance. Out of the 134 emails sent requesting participation, forty-three teachers responded and agreed to participate in the study. Thirty-four science teachers (who explicitly taught physical science; 24 HS and $10 \mathrm{MS}$ ) and only 9 math teachers (4 HS and $5 \mathrm{MS}$ ) responded to the request. All 24 high school teachers taught only physical science, responses from life science teachers have not been included because they did not cover unit conversions in their classes. I followed up with clarifying questions during in-person or phone interviews when survey responses were ambiguous. Middle school teacher participants were randomly selected solely based on the availability of teacher emails on the internet. Names of schools and counties along with teacher participants have been replaced with " $x x x$ " to maintain confidentiality. 132 college students who were primarily freshmen or sophomores enrolled in an introductory chemistry course were given a separate survey, shown in Appendix B. Fifty-four of these students were non-science majors in my college introductory chemistry class and 78 students were science majors in a class taught by another faculty member at our four-year university. A standard item analysis was carried out to determine the frequency of responses and the mode for the survey in Appendix A. Since the number of math teacher participants (9) was considerably less than the number of science teachers (24) who participated in this work, I did not carry out t-tests of significance which could lead to an over-estimation of the statistics. A similar approach was used to identify descriptive statistics for the student survey. The teachers' comments were divided into two categories; based on their perceptions of students' comfort levels and assessment of unit conversions on state standardized exams or inclusion of the topic in the school curriculum.

\section{Results and Discussion}

Contents of the first chapter from ten different physics and chemistry textbooks from different publishers used in introductory college science courses were analyzed to determine how unit conversions and the metric system was presented. This methodology was used because there is virtually no data on the content of introductory chapters in college textbooks and how students read and interpret scientific texts. Table 1 shows the similarities and differences in the content coverage of physics and chemistry texts. Across all ten books, the ubiquitous topics were an introduction to the scientific method, dimensional analysis, scientific notation, unit conversions and measurements. There were some content-specific differences for the two disciplines with chemistry texts typically introducing the nature of matter and its classification and the physics texts using more mathematical concepts of logarithms and trigonometry.

Table 1. An Analysis of the Contents of Chapter One in Ten Introductory Physics and Chemistry College Textbooks

\begin{tabular}{ll}
\hline Physics & Chemistry \\
\hline Physical quantities & Physical quantities and the scientific method \\
Dimensional Analysis & Dimensional Analysis \\
Units and conversions & Units and conversions \\
Scientific Notation & Scientific Notation \\
Measurement and significant figures & Measurement and significant figures \\
Logarithms & Accuracy and Precision \\
Trigonometry & Nature of matter: elements, compounds and mixtures \\
\hline
\end{tabular}


Since unit conversions was determined to be a common topic across physical science texts, the next logical step was to assess the level of preparation that students receive in school for this topic. As such, middle and high school STEM teachers were requested to complete the surveys in Appendix A to identify (a) how much instructional time was devoted to the topic of unit conversions within and to the SI system in science or math classes and (b) to identify if and how mastery of this important topic was assessed as part of standardized state tests and (c) to obtain teachers' perspectives on their student preparedness to do unit conversions. The teachers' responses and frequency counts are shown in Table 2. In some cases, teachers were unsure about how to answer the question or occasionally were not comfortable responding to it, those teacher responses have not been used and has caused the total number of responses to vary from the total number of participants. Frequency counts in Table 2 row 1 demonstrate that in high schools across the country, more science teachers ( $75 \%$ of the participants) spend time in their classrooms to the topic of unit conversions within the SI system, as compared to their math counterparts (25\%). Interestingly this topic appears to receive extremely scarce attention in middle schools- despite the fact that measurement is a topic included in the elementary grade band as suggested by the CCSS. This is further confirmed by the fact that both science and math middle school teachers have indicated that students do not have the required skills for doing unit conversions as seen from the responses to question number 7. Additionally, most high school teachers (both science and math) have indicated that they rarely or almost never cover unit conversions from English to SI units. The glaring disconnect seems to be the lack of questions on within SI unit conversions on standardized state exams. The majority of high school science and math teachers have indicated that there are not many instances where students get tested on converting between different units in the English-SI system.

Table 2. Statistics Showing Responses to Teacher Survey Instrument (Responses that were not clear are not included. For details on the Likert scale responses please see Appendix A.)

\begin{tabular}{|c|c|c|c|c|c|}
\hline \multirow{3}{*}{ Survey Question } & \multirow{3}{*}{ Options } & \multicolumn{4}{|c|}{ Participant Teacher Responses } \\
\hline & & \multicolumn{2}{|c|}{ Science } & \multicolumn{2}{|c|}{ Math } \\
\hline & & HS & MS & HS & MS \\
\hline \multirow{4}{*}{$\begin{array}{l}\text { How often do your students do unit } \\
\text { conversions within the SI system in } \\
\text { your science/math class? }\end{array}$} & Almost Never & 1 & 3 & 2 & 3 \\
\hline & Very Rarely & 3 & 3 & 1 & 1 \\
\hline & Occasionally & 8 & 4 & 0 & 1 \\
\hline & Routinely & 12 & 2 & 0 & 0 \\
\hline \multirow{4}{*}{$\begin{array}{l}\text { How often are students assessed on } \\
\text { converting units within the SI system on } \\
\text { standardized state high school } \\
\text { assessments? }\end{array}$} & No Questions & 3 & 5 & 2 & 3 \\
\hline & Very few & 14 & 5 & 1 & 2 \\
\hline & Some questions & 4 & 2 & 0 & 0 \\
\hline & Many questions & 1 & 0 & 0 & 0 \\
\hline \multirow{4}{*}{$\begin{array}{l}\text { How often do you require students to } \\
\text { convert from the English to SI system in } \\
\text { class }\end{array}$} & Almost Never & 11 & 12 & 3 & 5 \\
\hline & Very Rarely & 5 & 1 & 0 & 0 \\
\hline & Occasionally & 8 & 0 & 0 & 0 \\
\hline & Routinely & 0 & 0 & 0 & 0 \\
\hline \multirow{4}{*}{$\begin{array}{l}\text { How often are students required to } \\
\text { convert units within English-SI systems } \\
\text { on standardized state high school } \\
\text { assessments? }\end{array}$} & No Questions & 12 & 11 & 2 & 2 \\
\hline & Very few & 7 & 1 & 1 & 2 \\
\hline & Some questions & 2 & 0 & 0 & 1 \\
\hline & Many questions & 0 & 0 & 0 & 0 \\
\hline \multirow{3}{*}{$\begin{array}{l}\text { In your opinion are most of your } \\
\text { students comfortable doing metric } \\
\text { conversions within the SI system? }\end{array}$} & Yes & 9 & 3 & 0 & 1 \\
\hline & No & 13 & 9 & 3 & 4 \\
\hline & Unsure & 1 & 0 & 0 & 0 \\
\hline
\end{tabular}

The qualitative responses were classified into two main categories based on the results from the survey. A list of some teacher responses is presented verbatim in Table 3. The first column contains responses which were classified as their answers to student comfort levels with unit conversions. The second set of comments in Table 3 show teacher comments on the lack of questions on unit conversions on standardized assessments. 
Table 3. Teacher Comments on Survey Questions and Responses to Emails

Teacher perceptions on student levels of comfort on unit
conversions
Teacher 1 (personal communication)
My students are so dependent on calculators even on
simple operations and conversion problems is stressful for
them (sic) they would want to be told how to solve it
instead of exploring \& discovering how.

Teacher 2 (personal communication)

They totally understand the science. They cannot multiply and divide. Even by 10. Let alone 100, 1000, or more (sic). They do not know their times-tables, at all. They ask for a calculator to add $7+8$. I know you think I am crazy, but it is true. Students do not learn basic Math, spelling, or any grammar at all anymore. And they think I am nuts for expecting them to be able to do division, multiplication, hold place values of decimals, and such. And I teach advanced academic classes at xxx, supposedly a very good school. I am trying to get them to understand there are 100 $\mathrm{cm}$ in a meter. No way I am (sic) going for $2.54 \mathrm{~cm}$ in an inch!!

Teacher 12 (personal communication) I would say $30 \%$ of my students are comfortable with any conversion, whereas closer to $70 \%$ are comfortable converting to kilo-, centi- and milli-, but nothing else, and this discrepancy has been in line with incoming familiarity with exponents.

Teacher 7 (personal communication,)

The basic problem still remains with comfort rather than ability. Since the vast majority of their interactions with measurements in the "real world" are still in the English System, students see no value in exerting the energy to internalize SI.
Lack of standardized testing/inclusion in school curriculum of unit conversions

Teacher 5 (personal communication)

As chemistry teachers here at $\mathrm{xxx}$, we have been frustrated that unit conversions are not part of the xxx public school curriculum. This year, we have spent two weeks with the 9th grade biology students teaching them dimensional analysis in hopes this will better prepare them for chemistry the following year. Too much time is spent in the beginning of the year in chemistry working with students on this issue. It is not part of the xxx public school chemistry curriculum.

Teacher 9 (personal communication)

There are no standardized state high school assessments (HSA) in MD for physical science at all. In this state, there is only a state exam in Biology which is required for high school graduation. In $\mathrm{xxx}$ county, where I teach, there is a standardized county final exam for the introductory high school physics course. That standardized county exam does assess unit conversions within the SI system. English units are almost never used in class, and are not used at all on the county standardized final exam.

Teacher 11 (personal communication)

We are actually focusing our student goal this year on metric conversions (in 8th grade physical science) because we see the same issues at the end of our students' middle school science career. Even though we continually practice, for some reason they always do poorly on metric conversions on the SOL (Virginia Standards of Learning test).

Teacher 12 (personal communication)

My previous school in Lawrence, Massachusetts actually discouraged a focus on unit conversion, because it was not present on the standardized state test. However, when I taught A.P. Physics at another school, unit conversion was a point of emphasis and $100 \%$ of my students were proficient in the skill.

Some representative comments which did not fit into either of these categories but focused on how the curriculum has changed based on the standards are presented separately below.

Teacher xx (personal communication)

We use the SI system all the time but use the same units $(\mathrm{g}, \mathrm{ml})$ and do not usually have to convert them to something else.

Teacher xx (personal communication,)

I have been teaching for 36 years. There was a very big focus on this in the 80 's. I have seen it pretty much go away in math.

Teacher $\mathrm{xx}$ (personal communication)

We used to have students measuring in customary and metric units in the $6^{\text {th }}$ grade but we have not done so this year 
as we transition to the new standards.

Teacher $\mathrm{xx}$ (personal communication)

When I taught $7^{\text {th }}$ grade in the Transitions book we would spend a little time converting metric to English. However in the last few years except for giving some of our answers in metric units we have not converted.

These comments seem to indicate that the teachers are now moving away from using conversions. While using SI units (Teacher $\mathrm{xx}$ ) in class could be considered as conducting scientific measurements as aligned with the NGSS, the lack of specific language in the standards which would indicate that unit conversions be used to demonstrate dimensional analysis in middle and high schools would potentially benefit teachers and students. This would in turn help students understand multi-step dimensional analysis conversions in college classes.

Interestingly, while both the CCSS and the NGSS mention introducing the topic of measurement in the elementary grade band, neither has explicitly indicated a continued coverage of this basic topic in the high school course areas. Teacher \# 9 indicated that one county in the state of MD has a county-specific physical science assessment- which tests students on this topic. However, having just county-specific assessments may not be sufficient to ensure that all students have this core-concept literacy. Additionally, an examination of practice math PARCC questions did not show any questions explicitly requiring students to convert between units either as stand-alone questions or as part of a bigger word problem.

As mentioned before, one of the major goals of this study was to identify why this topic was a problematic issue for students. Accordingly, the student survey was designed to identify the problematic areas for students in unit conversions. Appendix B shows the survey instrument that was given to college students enrolled in an introductory chemistry class towards the end of one semester of college. Table 4 shows the student responses to items 5 , 6 and 7 of the student survey. It is very discouraging that only $9 \%$ of declared college science majors feel they are fluent in this basic topic. The vast majority of students ( $81 \%$ of declared science majors and $65 \%$ of non-science majors) appear to require between 1 to 3 weeks, to review this concept in college. Even more discouraging is the statistic that shows that $10 \%$ of science majors are not comfortable with the concept after one semester of a college level science course. Additionally, almost $50 \%$ of science majors indicate that the biggest challenge in the course for them is the transferability of math skills to chemistry. While the students' self-reports suggest that only $10 \%$ of the survey sample feel uncomfortable with metric conversions after one semester of an introductory college course, as mentioned in the rational for the study section, the data from a question on unit conversions given on a final exam on a previous semester shown more discouraging results where $41 \%$ of the students got the conversion wrong. This also shows that students may over-estimate their skill-sets and understanding on some topics.

Table 4. Statistics Showing Responses to Items 5, 6 and 7 on Student Survey Instrument

\begin{tabular}{|c|c|c|c|}
\hline \multirow[t]{2}{*}{ Survey Question } & \multirow[t]{2}{*}{ Responses } & $\begin{array}{l}\text { Non-Science } \\
\text { Majors }\end{array}$ & $\begin{array}{l}\text { Science } \\
\text { Majors }\end{array}$ \\
\hline & & $\mathrm{N}=54$ & $\mathrm{~N}=78$ \\
\hline \multirow{8}{*}{$\begin{array}{l}\text { How much time did you } \\
\text { spend re-learning the } \\
\text { metric system for this } \\
\text { course? } \\
\text { Which portion of the } \\
\text { metric conversions do } \\
\text { you find most difficult? }\end{array}$} & None- very fluent & $17 \%$ & $9 \%$ \\
\hline & First week & $43 \%$ & $54 \%$ \\
\hline & Between 2-3 weeks & $22 \%$ & $27 \%$ \\
\hline & Still struggling with prefixes and conversions & $19 \%$ & $10 \%$ \\
\hline & Remembering the order of the SI prefixes & $46 \%$ & $42 \%$ \\
\hline & $\begin{array}{l}\text { Remembering if the decimal needs to shift to the left or } \\
\text { right or to multiply or divide }\end{array}$ & $22 \%$ & $37 \%$ \\
\hline & $\begin{array}{l}\text { Writing the answers in scientific notation because I can't } \\
\text { do math very well }\end{array}$ & $11 \%$ & $8 \%$ \\
\hline & All of the above & $19 \%$ & $14 \%$ \\
\hline \multirow{4}{*}{$\begin{array}{l}\text { My biggest challenge } \\
\text { for this course is }\end{array}$} & The math skills required to do chemistry & $15 \%$ & $8 \%$ \\
\hline & Application of the math skills to chemistry concepts & $33 \%$ & $42 \%$ \\
\hline & Learning and applying new vocabulary in chemistry & $31 \%$ & $41 \%$ \\
\hline & All of the above & $7 \%$ & $8 \%$ \\
\hline
\end{tabular}




\section{Implications for Curriculum Design and Teaching}

The topic of unit conversions investigated in this paper is a central concept that bridges mathematics and science. While this study simply focuses on just that one topic- it further reifies that premise because the school teachers have indicated a variable level of coverage. The SI system is used in all of the physical science content courses in schools and college. As shown in Table 1, introductory college-level physical science textbooks routinely include the topic of unit conversions in the first chapter, highlighting its importance and the fundamental nature of the concept in the discipline of physics and chemistry. Additionally, college faculty may or may not spend adequate time on the first chapter assuming that students taking a college level science course would have this basic knowledge to start the course. Even if students do not intend to major in a STEM discipline, they are required to take some science classes as part of their core graduation requirements. As such, a working knowledge of this concept is expected from someone who has graduated high school. Furthermore, teacher responses to their perception of student competency for doing unit conversions shows an alarming reality- the vast majority of middle and high school math and science teachers are aware that students have not mastered this fundamental concept (see question 7, Table 2) indicating that they are not really ready to take college-science courses. Table 3 indicates that $42 \%$ of science majors are aware that they are not well prepared and do not necessarily remember the order of the metric prefixes as well as not know how to shift the decimal point for within metric conversions. When they spend two weeks out of a 14 week semester to re-learn basic material, it leaves them with less time to master the more complex college-level material which puts them at risk for failing the course. When students are not prepared to use these basic concepts from the get-go in college several students require remedial math classes in their early years in college, which puts them further behind for graduation.

The CCSS built on the NCTM's Principles and Standards for School Mathematics (2000) and the NGSS identify "measurement" as a key cross-connecting and discipline-specific topic and emphasize instructional practices and the specific mathematical and science content for each grade band in the US. The term measurement could be construed loosely. The first step would be to have common guidelines which explicitly indicate that unit conversions within SI and English-SI systems be part of the curriculum would ensure that there is less variability in the content coverage. The current NGSS standards suggest following a spiral curriculum where ideas introduced in the earlier grades are intended to be built-on the mathematics and science curricula in higher grades. However, prior research has shown that despite having common guidelines they may not get implemented uniformly in classrooms (Ottmar et al., 2013). This seems to be reflected in the current study as well. Clearly, as one of the teachers has indicated (Table 2), they were discouraged from reifying the metric concept in their high school because it was not mandated as a state assessment item. However, when this same teacher taught in a different school in a different state, all of their students were proficient in this topic. In school systems where teachers are not discouraged, they may very well be reifying the topic for their students in high schools. Another teacher who used to teach customary to SI conversions prior to the introduction of NGSS/CCSS has now stopped teaching that to their sixth graders (miscellaneous comments above). Two of the teacher comments indicate the lack of connectivity of US students to the metric measurements system because it is not part of their daily lives. For this reason, it is even more critical that the comparability between the English and metric systems be emphasized in schools. For question 6 on the student survey "which portion of the metric conversions do you find most difficult", $42 \%$ of science and $46 \%$ non-science majors have indicated that they find retaining the order of the metric prefixes challenging. What is equally disconcerting is the percentage of students who indicate they are unaware of how the decimal place moves during conversions as well as writing answers in scientific notation.

\section{Future Research Questions for STEM Education and Assessment}

This study raises several questions for current and future research as well as defining scientific literacy in the $21^{\text {st }}$ century. As Table 2 shows, teachers in all five states indicate that standardized tests lack questions that assess students on this connection. What is the point of having common standards without having an assessment to go with it that actually uses questions that test college and career readiness? What is the role of state-wide assessments and what do they test students on in terms of college and career readiness? What is scientific literacy in terms of "college readiness" for taking college courses in the sciences besides having students take advanced placement classes? The PARCC test was supposed to be designed to address college readiness. Then why are there no questions on this topic on the practice math PARCC administered to middle school students? Students all over the world internalize the metric system as a part of daily life. American students do not get that opportunity to get a visual estimate of the amount of material in 100 grams versus a kilogram, as part of their daily life. However, one thing is clear. If the 
science standards for the next generation are set for college readiness, the ability to do metric conversions should be second nature for all students who graduate high school and all teachers nationwide should feel confident that their students can do this basic math. Dissemination of these results is intended as a small step to highlight that this is an issue which needs to be brought forward to the science and mathematics educators' community. School administrators, curriculum specialists and everyone involved in educating the next generation needs to be mindful of how we assess and prepare students in science and math for college readiness.

\section{References}

Adodini, R., Harris, B., Atkins-Burnett, S., Heaviside, S., Novak, T., \& Murphy, R. (2009). Achievement effects of four early elementary school math curricula: Findings from first graders in 39 schools-Executive Summary (NCEE 2009-4053). Washington D.C; National Center for Education Evaluation and Regional Assistance, Institute of Education Sciences, U.S.Department of Education.

Angel, S.A., \& Lalonde, D.E. (1998). Science success strategies: An interdisciplinary course for improving science and mathematics education. Journal of Chemical Education, 75(11), 1437-1441. https://doi.org/10.1021/ed075p1437

Bodner, G. M., \& Domin D.S. (2000). Mental models: the role of representations in problem-solving in chemistry. University Chemistry Education, 4(1), 24-30.

Butterfield, A., Sutherland, R., \& Molyneux-Hodgson, S. (2011). Learning conversions in science: the case of vocational students in the UK. Research in Learning Technology, 8(3). https://doi.org/10.3402/rlt.v8i3.12009

Common Core State Standards Initiative. (2010). Common Core State Standards for Mathematics. Retrieved from http://www.corestandarsd.org

Conley, D. T. (2007). Redefining college readiness. Eugene, OR: Educational Policy Improvement Center.

Deampfle, P. A. (2003). An analysis of the high attrition rates among first year college science, math and engineering majors. Journal of College Student Retention: Research, Theory and Practice, 5(1), 37-52. https://doi.org/10.2190/DWQT-TYA4-T20W-RCWH

deAraujo, Z., Jacobson, E., Singletary, L., Wilson, P., Lowe, L., \& Marshall, A. (2013). Teachers' conceptions of integrated mathematics curricula. School Science and Mathematics, 113(6), 285-296. https://doi.org/10.1111/ssm.12028

Dincer, E. M., \& Osmanoglu, A. (2018). Dealing with metric unit conversion: An examination of prospective science teachers' knowledge of and difficulties with conversion. Science Education International, 29(3), 174-182.

Gifford, V. D., \& Harpole, S. (1986). Factors contributing to freshmen physics achievement Memphis. TN: Mid-South Educational Research Association. (ERIC Document Reproduction Service No. ED 278 554.)

Haffner, R. W. (1969). Placement of freshmen in the chemistry program. Journal of Chemical Education, 46(3), 160-162. https://doi.org/10.1021/ed046p160

Hart, G. E., \& Cottle, P. D. (1993). Academic backgrounds and achievement in college physics. The Physics Teacher, 31, 470-475. https://doi.org/10.1119/1.2343848

Johnson, M., \& Kuennen, E. (2006). Basic math skills and performance in an introductory statistics course. Journal of Statistics Education, 14, 2, https://doi.org/10.1080/10691898.2006.11910581

Legg, M. J., Legg, J. C., \& Greenbowe, T. J. (2001). Analysis of Success in General Chemistry Based on Diagnostic Testing Using Logistic Regression. Journal of Chemical Education, 78(8), 1117-1121. https://doi.org/10.1021/ed078p1117

Ludwig (2016). How are the metric system and SI different? Retrieved 2019, May 2 from https://www.quora.com/how-are-the-metric-system-and-si-different

McFate C., \& Olmsted J. (1999). Assessing student preparation through placement tests. Journal of Chemical Education, 76, 562-565. https://doi.org/10.1021/ed076p562

McLoyd, V. C. (1998). Socioeconomic disadvantage and child development. American Psychologist, 53(2), 185-204. https://doi.org/10.1037/0003-066X.53.2.185

Next Generation Science Standards. (2013). Next Generation Science Standards. Retrieved from 
http://www.nextgenscience.org

Ottmar, E. R., Konold, T. R., Berry, R. Q., Grissmer, D. W., \& Cameron, C. E. (2013). Increasing equity and achievement in fifth grade mathematics: The contribution of content and exposure. School Science and Mathematics, 113(7), 345-355. https://doi.org/10.1111/ssm.12035

Reynolds, A. J., \& Walberg, H. J. (1992). At structural model of science achievement and attitude: An extension to high school. Journal of Educational Psychology, 84, 371-382. https://doi.org/10.1037/0022-0663.84.3.371

Russell, A. A. (1994). A rationally designed general chemistry diagnostic test. Journal of Chemical Education, 71(4), 313-317. https://doi.org/10.1021/ed071p314

Sadler, P. M., \& Tai, R. H. (2001). Success in introductory college physics: The role of high school preparation. Science Education, 85, 111-136. https://doi.org/10.1002/1098-237X(200103)85:2\%3C111::AID-SCE20\%3E3.0.CO;2-O

Schwartz, M., Sadler, P. M., Sonnert, G., \& Tai, R. H. (2009). Depth versus breadth: How content coverage in high school science relates to later success in college science coursework. Science Education, 93(4), 798-826. https://doi.org/10.1002/sce.20328

Shumba, O., \& Glass, L.W. (1994). Perceptions of coordinators of college freshman chemistry regarding selected goals and outcomes of high school chemistry. Journal of Research in Science Teaching, 31, 381-392. https://doi.org/10.1002/tea.3660310407

Sirin, S. R. (2005). Socio-economic status and academic achievement: a meta-analytic review of research. Review of Educational Research, 75(3), 417-453. https://doi.org/10.3102/00346543075003417

Sokolowski, A. (2015). Recognizing prefixes in scientific quantities. The Physics Teacher, 53, 358-359. https://doi.org/10.1119/1.4928352

Swanson, C. B., \& Stevenson, D. L. (2002). Standards-based reform in practice: Evidence on state policy and classroom instruction from the NAEP state assessments. Educational Evaluation and Policy Analysis, 24(1), 1-27. https://doi.org/10.3102/01623737024001001

Tai, R. H., \& Sadler, P. M. (2007). High school chemistry instructional practices and their association with college chemistry grades. Journal of Chemical Education, 84(6), 1040-1046. https://doi.org/10.1021/ed084p1040

Tai, R. H., Sadler, P. M., \& Loehr, J. F. (2005). Factors influencing success in introductory college chemistry. Journal of Research in Science Teaching, 42(9), 987-1012. https://doi.org/10.1002/tea.20082

Weiss, I. R., Pasley, J. D., Smith, P. S., Banilower, E. R., \& Heck, D. J. (2003). Looking inside the classroom: A study of K-12 mathematics and science education in the United States-highlights report. Chapel Hill, NC: Horizon Research.

U.S. Department of Education. (2010). U.S. Department of Education. Retrieved from http://eddataexpress.ed.gov

Wagner, E., Sasser, H., \& DiBiase, W.J. (2002). Predicting Students at Risk in General Chemistry Using Pre-semester Assessments and Demographic. Journal of Chemical Education, 79(6), 749-755. https://doi.org/10.1021/ed079p749

West, G. A. (1932). Influence of high school science on grades in college chemistry. School Science and Mathematics, 32, 911-913. https://doi.org/10.1111/j.1949-8594.1932.tb16581.x

Yager, R. E., Snider, B., \& Krajcik, J. (1988). Relative success in college chemistry for students who experienced a high school course in chemistry and those who had not. Journal of Research in Science Teaching, 25, 387-396. https://doi.org/10.1002/tea.3660250506 


\section{Appendix A}

1. Level taught
A. Middle School
B. High School

2. Subjects taught primarily
A. Biology
B. Chemistry
C. Physics
D. Earth Science
E. Mathematics

3. How often do your students do unit conversions within the SI system in your science/math class?
A. Almost never
B. Very rarely (1-2 times /month)
C. Occasionally
D. Routinely (few problems every week)

4. How often are students assessed on converting units within the SI system on standardized state high school assessments?
A. No questions in any physical science/math assessment requires them to do this
B. Very few questions
C. Some questions
D. Many questions

5. How often do you require students to convert from the English to SI system in class?
A. Almost never
B. Very rarely (1-2 times /month)
C. Occasionally
D. Routinely (few problems every week)

6. How often are students required to convert units within English-SI systems on standardized state high school assessments?
A. No questions in any physical science/math assessment requires them to do this
B. Very few questions
C. Some questions
D. Many questions

7. In your opinion are most of your students comfortable doing metric conversions within the SI system?
A. Yes
B. No
C. Unsure 


\section{Appendix B}

1. During high school, how often did you do unit conversions within the SI system in your science class?
A. Almost never
B. Very rarely (1-2 times /month)
C. Occasionally
D. Routinely (few problems every week)

2. How often were you required to convert units within the SI system on standardized state science or math high school assessments?
A. Almost never
B. Very rarely (1-2 times /month)
C. Occasionally
D. Routinely (few problems every week)

3. How often were you required to convert from the English to SI system in your high school science class?
A. Almost never
B. Very rarely (1-2 times /month)
C. Occasionally
D. Routinely (few problems every week)

4. How often were you required to convert units within English-SI systems on standardized state science or math high school assessments?
A. Almost never
B. Very rarely (1-2 times /month)
C. Occasionally
D. Routinely (few problems every week)

5. How much time did you spend re-learning the metric system for this course?
A. None- I was very fluent in it
B. About a week in the early part of the semester
C. Between 2 to 3 weeks
D. Still struggling with the prefixes and conversions

6. Which portion of the metric conversions do you find most difficult?
A. Remembering the order of the SI prefixes
B. Remembering if the decimal needs to shift to the left or right or to multiply or divide
C. Writing the answers in scientific notation because I can't do math very well
D. All of the above

7. My biggest challenge for this course is
A. The math skills required to do chemistry
B. Application of the math skills to chemistry concepts
C. Learning and applying new vocabulary in chemistry
D. All of the above 